This item was submitted to Loughborough's Research Repository by the author.

Items in Figshare are protected by copyright, with all rights reserved, unless otherwise indicated.

\title{
Integrating design in the project process
}

PLEASE CITE THE PUBLISHED VERSION

PUBLISHER

(c) Institution of Civil Engineers / Thomas Telford

VERSION

AM (Accepted Manuscript)

LICENCE

CC BY-NC-ND 4.0

REPOSITORY RECORD

Austin, Simon A., Andrew N. Baldwin, Baizhan Li, and Paul R. Waskett. 2019. "Integrating Design in the Project Process". figshare. https://hdl.handle.net/2134/4067. 
This item was submitted to Loughborough's Institutional Repository (https://dspace.lboro.ac.uk/) by the author and is made available under the following Creative Commons Licence conditions.

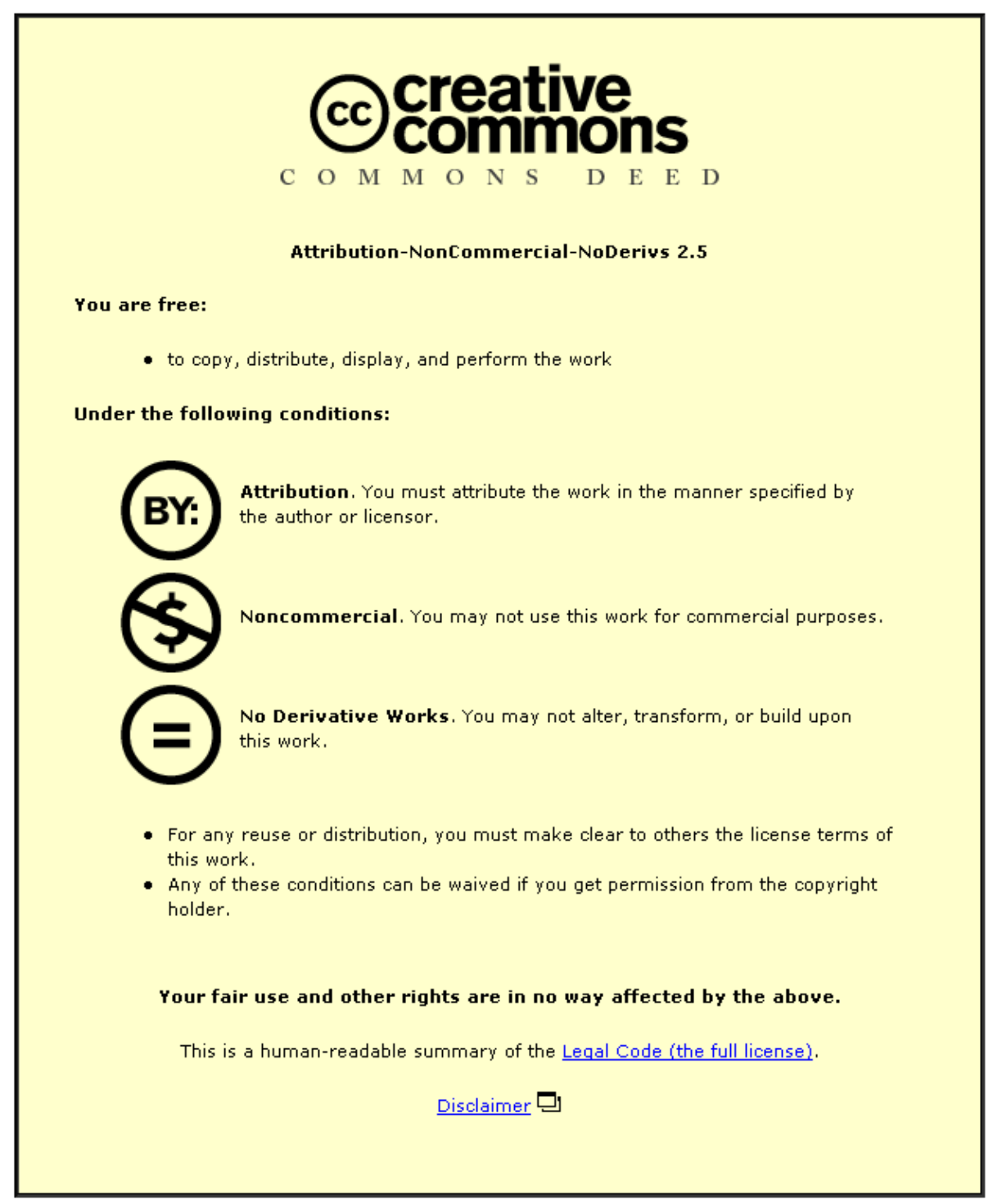

For the full text of this licence, please go to: http://creativecommons.org/licenses/by-nc-nd/2.5/ 
Paper title: Integrating Design in the Project Process

Authors: $\quad$ Simon Austin, BSc, PhD, CEng, MICE, FCS

Professor of Structural Engineering

Department of Civil and Building Engineering, Loughborough University

Andrew Baldwin, BSc, MSc, PhD, CEng, MICE, CIOB

Professor and Head of Department

Department of Civil and Building Engineering ,Loughborough University

Baizhan Li, BSc, MSc, PhD

Research Assistant

Department of Civil and Building Engineering, Loughborough University

Paul Waskett, BEng, PhD

Design Management Engineer

AMEC Construction, Stratford-on-Avon

Keywords: $\quad$ Management, Design, Integration, Planning, Scheduling 


\section{Synopsis}

Current engineering design planning practice takes little account of the interdisciplinary, iterative nature of the process. This leads to a compromised design process containing inevitable cycles of rework together with associated time and cost penalties in both design and construction. The Analytical Design Planning Technique (ADePT) is a planning methodology which helps to overcome these difficulties. This paper describes the development and application of the technique. The technique can be applied as a risk identification and change management tool, as well as its primary purpose as a planning system. It also identifies co-ordination requirements and changes to design practices in achieving co-ordination. The benefits of using ADePT to integrate the project process are also described. 


\section{Introduction}

The Egan report identified the separation of design from the rest of the project process as a fundamental weakness in the construction industry: a significant re-balancing is required to integrate design with construction and performance and to ensure that issues such as flexibility of use, operating and maintenance costs and sustainability are considered in the design and planning stages of a project. The report also states that there is scope for the introduction of tools and techniques to facilitate this integration, and this paper reports the development of such a method. The Analytical Design Planning Technique (ADePT) can assist effective planning and management of design activity within the complete project context. It has been developed at Loughborough University through research funded by the DETR, EPSRC and a group of industrial collaborators (AMEC Design, BAA, Boots, Laing, Ove Arup \& Partners and Sheppard Robson) who have recognised the need for a more harmonised project process. Following testing on three projects, the technique and prototype software is now being applied by the collaborators on a range of projects, including office developments, refurbishments, hospitals and pharmaceutical buildings (figure 1). There have been a total of seven applications to date on projects ranging in value from $£ 2-160 \mathrm{M}$.

The attendance of approximately 150 people at an evening meeting at the ICE on ADePT, and the attainment of 'Achievement through Innovation' and 'Supreme' Quality in Construction Awards in 1999, gives an indication of the industry's interest in the technique, and other events on the process of design and its management provide evidence of the growing recognition of their importance to the success of a project. 


\section{The Analytical Design Planning Technique}

The Analytical Design Planning Technique (ADePT), which has been developed over the last six years (Austin ${ }^{1}$ ), consists of three main components, as indicated in figure 2: a model of the design process defining activities and their information requirements, the principal driver of design development (Austin²); a Dependency Structure Matrix (DSM) analysis tool which is linked to the model via a database and identifies the optimal sequence of tasks and iteration within the design process (Austin ${ }^{3}$ ); and a design programme which is integrated with the project plan through further DSM analysis

A model can represent a design process at a generic level: that is to say it can incorporates activities and information that can describe the design of a wide variety of projects. An example of a diagram from a process model is shown in figure 3. Testing of ADePT has shown that it is possible to develop models where over $90 \%$ of the necessary activities are included to define the design of a project $\left(\right.$ Austin $^{2}$ ). This confirms the views made in Rethinking Construction $\left(\mathrm{DETR}^{5}\right.$ ) about the repeat nature of construction projects and the need for standardisation of processes as well as products: within various categories of project, such as buildings, tunnels, bridges, process plants, and so on (figure 4), the products may vary significantly, however the design processes are largely repeatable.

A simple example of a Dependency Structure Matrix (DSM), the second part of ADePT, is demonstrated in figure 5. In figure 5(a) it can be seen that design tasks are listed alphabetically within disciplines in the rows of the matrix. The order is mirrored in the columns. A mark in the matrix represents a dependency of the task in the row upon the task in the column. The dependencies are weighted on a three point scale $(A, B, C)$ on the basis of the strength of dependency, sensitivity of the receiving task to changes in the information and the ease with 
which the information can be estimated. Dependencies weighted A or B are considered critical, while $\mathrm{C}$ is not essential to the task and does not contribute to iteration in the process. If design is undertaken in the order on the matrix from top-left to bottom-right, the shaded area indicates a need for iteration within the process. Figure 5(b) shows the matrix following analysis to determine the optimal sequence of tasks such that iteration is reduced to a minimum. It can be seen that the number of critical marks above the diagonal and the size of iteration within the process have been reduced.

In the final part of ADePT, the sequence of tasks in the DSM is transferred to a project management program to create a programme of the design process by the addition of resources and duration. The 'loops' of iterative work can be programmed to ensure the design is developed efficiently and the optimal programme provides a starting point for the integration of design within the project process, an operation that involves further analysis of the DSM.

\section{Improving the Design Process}

The Egan report $\left(\mathrm{DETR}^{5}\right)$ identifies the need for designers to work in close collaboration with the other participants in the project process, and above all this must mean other designers. In current practice, tasks undertaken by different designers are not as well co-ordinated as those by a single designer because of a lack of understanding of the entire design process. Testing of ADePT has shown that interdependent loops of design activity highlighted within the matrix correspond to areas of the design requiring careful co-ordination (Austin ${ }^{3}$ ). The activities in these loops are more often than not undertaken by more than one designer and hence coordination of work is required. 
The integration of stages of a project and team members within each stage requires not only changes to the way a project is managed, but to the way the team members behave and interact. Where the design team may be co-located or expected to develop the design through a series of workshops, this suggests a change to the way complex co-ordination is approached. The blocks of interdependent design activity require a concerted management effort, rigorous review strategy and a strong link to the client's decision making and approval processes. They also highlight where a concurrent, collaborative working strategy is appropriate for the design team members, who must liase closely in all decisions, understand each others' design requirements and constraints, and have confidence in each others' commitment to the achievement of a common aim. The fulfilment of these ambitions can be encouraged through the co-location of members of the design team or, where this is impractical, via the implementation of effective electronic communication techniques. These working practices cannot be applied without changes to the culture in the design team and project in general, but the identification of coordination issues through Dependency Structure Matrix analysis provides an opportunity for project management to plan and control the related activities effectively. The testing of ADePT has shown that there are a range of methods for planning, undertaking and managing these areas of design, and that the appropriate method is a function of the project nature, design issue (scale and complexity), team structure and programme. As such, when determining an approach to planning and management of these issues, they need to be examined in their own right. However, the identification of these issues, and the implication of re-addressing heavily interdependent sections of design following their completion, means that the matrix can be used as a guide to the timely review and approval of design.

A major problem during the design process is a failure to deal effectively with variations, the cause of delays and associated cost increases as the design progresses and construction is 
undertaken. The graphical nature of a Dependency Structure Matrix allows the impact of changes and variations to be envisaged quickly and easily. This can be achieved simply by moving tasks within the matrix (usually down the order) to simulate them being undertaken following the change. The tasks that must then be re-examined are clearly indicated by the matrix. This is a particularly useful feature where the work of one design discipline is affected by the decisions of another, or where the design in general is delayed by the decisions of the client.

A further area where designers need to work together is in the co-ordination of work between the design stages, thus ensuring that adequate design development is undertaken in each discipline to provide the required cost certainty and confidence to the client that the project will be successful. There is current research aimed at defining the project process across all stages, thus facilitating an integrated process (details of which are available from the authors). This will provide a means of identifying the timely introduction of suppliers into the design process, a benefit that is beginning to be seen from the implementation of ADePT, as described later in this paper.

The Analytical Design Planning Technique provides the Design Manager with guidance as to the areas of design that require particularly careful planning and control. It also helps to organise teams, tackle design in a focused way, and to identify and control changes in the design. As such, the technique provides a means of improving the undertaking and management of the design process; additionally ongoing analysis with the technique allows the design and construction processes to be integrated, as described below.

\section{Integrating Design and Construction}


Scheduling the design process with $\mathrm{ADePT}$ identifies the optimal sequence of tasks to satisfy the development of a design solution. This means that the programme produced in the final stage of the technique’s implementation represents this optimal design process. In practice, it is highly unlikely that this sequence will be realistic because of the constraints put on the process by the need to deliver a building in a short a timescale as possible: the design, procurement and construction processes overlap and therefore design information must be released to contractors before the ideal time. A knowledge of the optimal design sequence, when combined with a view of the ideal construction sequence (which is relatively easy to determine with the use of readily available project planning tools), provides a good starting point to integrate design within the wider project process, a necessary requirement of the industry identified by Egan. Figure 6 depicts the philosophy of integrating design and construction processes and programmes. This integration is not straight-forward, as the two processes do not fit together comfortably. In order that they are integrated, the constraints that each process puts on the other must be considered. For example, sub-structures are often one of the last components to be designed (ideally), but they are one of the first to be required on site which means there is usually a need to design them out of the optimal order i.e. the construction process imposes a constraint upon design. (Figure 7). As can be seen, moving a task in the optimised DSM results in some critical information placed above the diagonal. In order that this does not create interdependencies within a large proportion of the design process, the information must be dealt with in a way that ensures it does not need to be revisited at a point later in the process, by fixing or conservatively estimating the information.

Figure 6 indicates the outcome of integrating the two processes: constrained (or sub-optimal) design and construction processes (with corresponding programmes); a procurement strategy that is mutually agreed by consultants and contractors following objective decisions about the 
impact of incorporating constraints; and a schedule of the risks in the design. This schedule is produced through the analysis of the constraints on the design process: the cost of fixing or estimating information within the design can be compared against the risk of not doing so, thereby allowing the engineering economics in design to be assessed and logged in a risk register. As such, ADePT can act as a tool to compliment risk management. It identifies areas of design where risks are present, illustrates the scale of risk in the design process itself (in a similar way to an evaluation of the effects of change, described above) and contributes to the development of a legacy risk register for use in future projects.

Having established an approach to undertaking the design and an agreed procurement strategy, the design associated with each contract can be examined to determine whether it is best undertaken by a consultant, contractor or sub-contractor. In some cases, it may appear logical that the contractor is not involved in design until a late stage in the process, however it could prove beneficial to introduce their expertise earlier if the design of the relevant systems and elements required careful co-ordination with other contracts (either in the design itself, or on site). Alternatively, it may seem sensible to introduce contractors early in the process (to encourage as much of an integrated project as possible), although this may result in an uneven design workload while they wait for consultants or other contractors to develop their own design. This can result in money being paid in the form of a retainer while no work is being undertaken in return, and increased costs associated with contractual arrangements such as twostage tendering. Therefore, it might prove beneficial to delay the introduction of the contractor.

The matrix analysis stage of $\mathrm{ADePT}$ also provides a means of assessing the impact of each package of work upon the others, and the need for co-ordination between them. This is in accordance with Egan's call for integration within the project supply chain, and the application 
of ADePT to the fabrication design stage (production information) of a project is being examined as part of related research project Integrated Collaborative Design (full details of which are available from the authors). This will determine strategies for integrating contractors and suppliers into the consultants' design process in a manner that is both timely and that allows the design co-ordination and contracts to be effectively managed. The key to this approach is that participants should be introduced into the project early enough to allow their design to be co-ordinated with other parts of the project, and as late as possible such that their design is not constrained by decisions made by the consultant. This concept is beginning to be termed the 'last responsible moment' and applies to the design process in general where delaying decisions helps to maintain flexibility in the design for as long as possible.

\section{Conclusions}

The Analytical Design Planning Technique (ADePT) offers an approach to planning, executing and managing design in a more effective and efficient manner to that which is typical of current practice. The technique provides benefits in the design at a number of levels. Firstly, it helps to deliver improvements in the design process. This is achieved by identifying the optimal plan of work based on the flow of information between designers, establishing areas of work that require careful co-ordination, and encouraging members of the design team to work together in a collaborative manner that facilitates the production of a co-ordinated design solution. This approach to design development and co-ordination should also result in a reduction in designrelated problems on site, and the production of shorter and more robust design programmes with the associated effect of an increase in competitiveness of design fees. The technique also provides a means of integrating the design and construction processes in a structured, objective manner, thus developing an optimal 'project process' and an agreed procurement strategy that suits the way this integration has been achieved. A further benefit of the application of ADePT is 
in the analysis of the constraints on the design process, such as changes or delays and requirements from the construction process. Overall, the Analytical Design Planning Technique provides a range of benefits in design planning and management (and the design itself). Feedback from industry suggests that the technique has the potential to improve the planning of design in a manner similar to the effect of the Critical Path Method on the planning of construction work some thirty years ago. Training of planners and designers in the collaborating organisations is now underway as the technique is being implemented on live building projects.

\section{Acknowledgements}

This work has been undertaken as part of a research grant funded by the EPSRC, DETR and industry (AMEC Design, Ove Arup and Partners, BAA, Boots, Laing and Sheppard Robson) under the LINK Integration in Design and Construction (IDAC) programme.

\section{References}

1. AUSTIN, S., BALDWIN, A. \& NEWTON, A., A data flow model to plan and manage the building design process. Journal of Engineering Design, 1996, 7, No. 1, 3-25.

2. AUSTIN, S., BALDWIN, A., LI, B. \& WASKETT, P., Analytical Design Planning Technique (ADePT): an IDEF0v model of the detailed building design process. Accepted for publication in Design Studies, 1998.

3. AUSTIN, S., BALDWIN, A., LI, B. \& WASKETT, P., Analytical Design Planning Technique (ADePT): a Dependency Structure Matrix tool to schedule the building design process. Accepted for publication in Construction Management and Economics, 1998. 
4. AUSTIN, S., BALDWIN, A., LI, B. AND WASKETT, P., Analytical Design Planning Technique (ADePT): Programming the Building Design Process Accepted for publication in Structures and Building, 1998.

5. Rethinking Construction, Department of the Environment, Transport and the Regions, ISBN 185112094 7, 1998.

6. BALDWIN, A., AUSTIN, S. \& PENDLEBURY, M., The Interface of Early Design and Cost Advice in the Building Design Process. ARCOM Conference, Cambridge, UK, 1997, pp 395-404. 


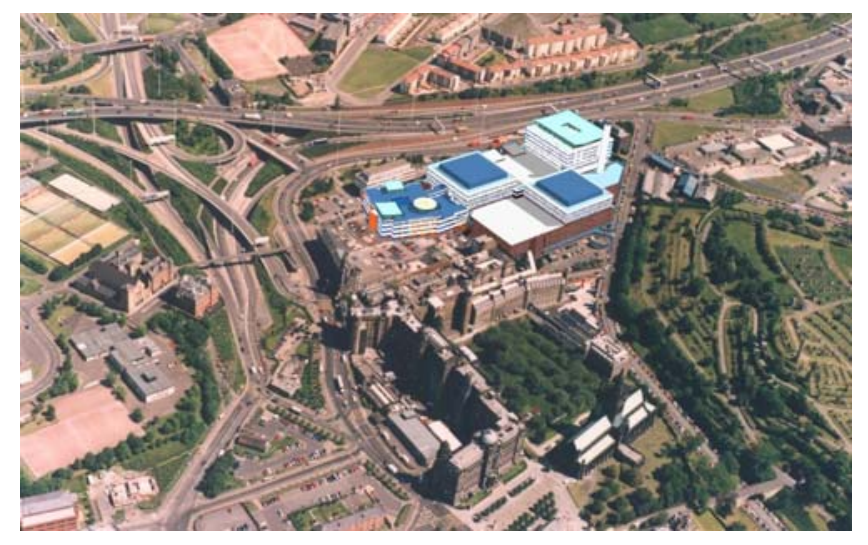

Figure 1 The Burns/Plastic Surgery and Emergency Receiving Unit at Glasgow Royal - the first project to apply ADePT 


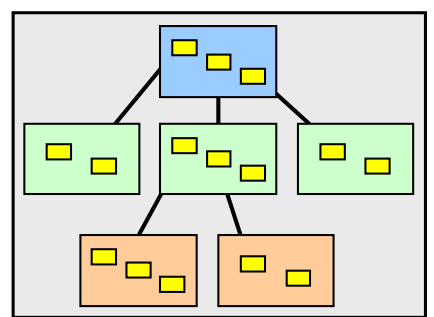

Design Process Model

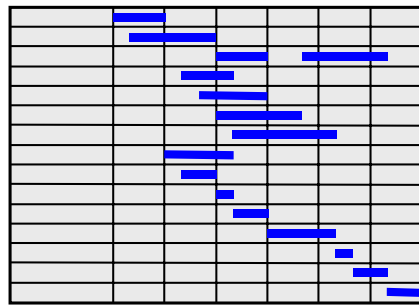

Project and Discipline Design Programmes

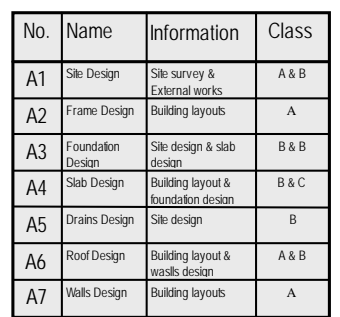

Information

Dependency Table

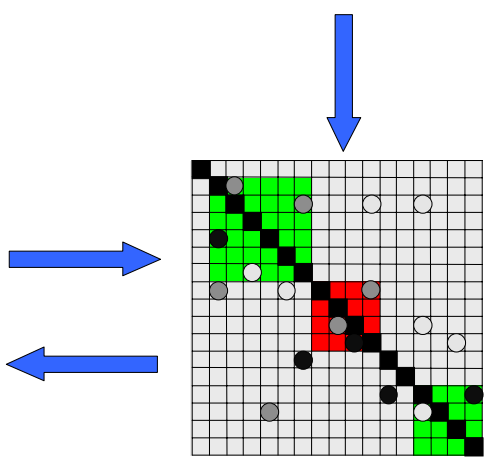

Dependency Structure Matrix Analysis

Figure 2 The Analytical Design Planning Technique 


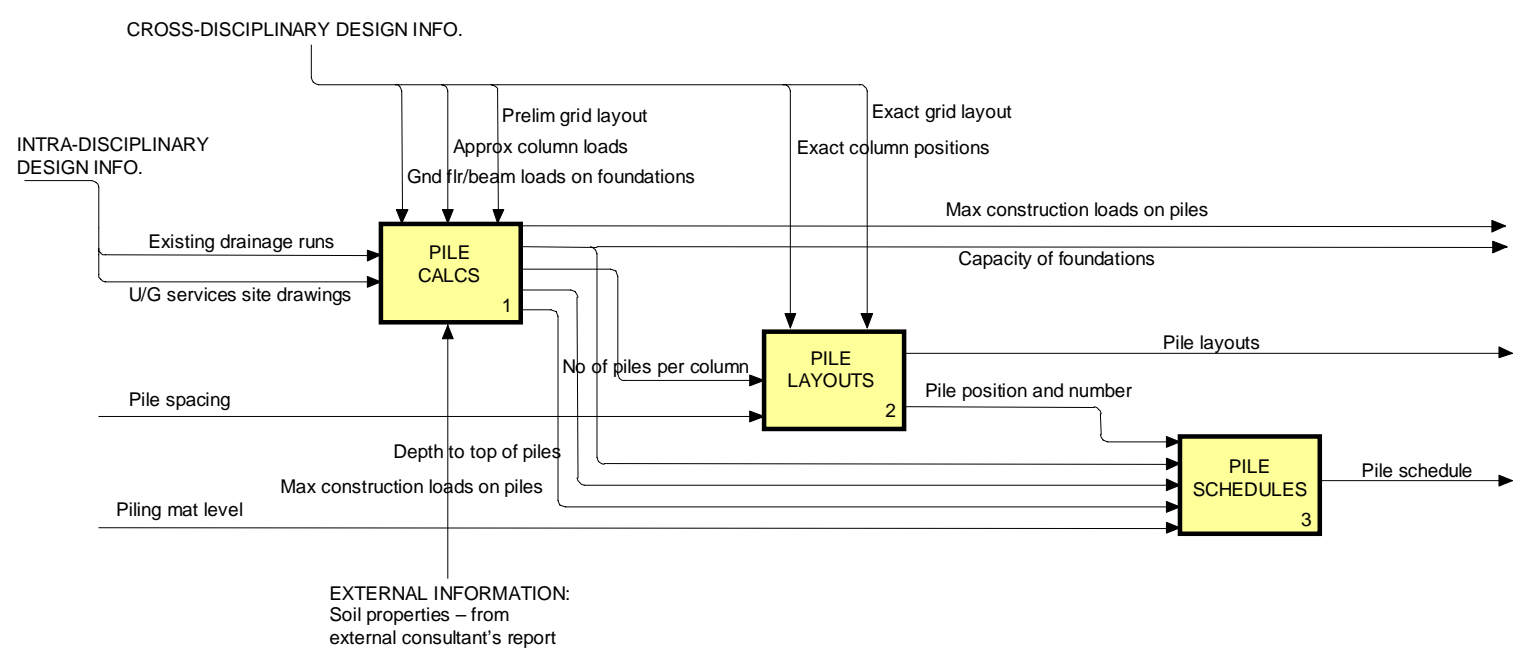

Figure 3 An example of a diagram from a design process model 

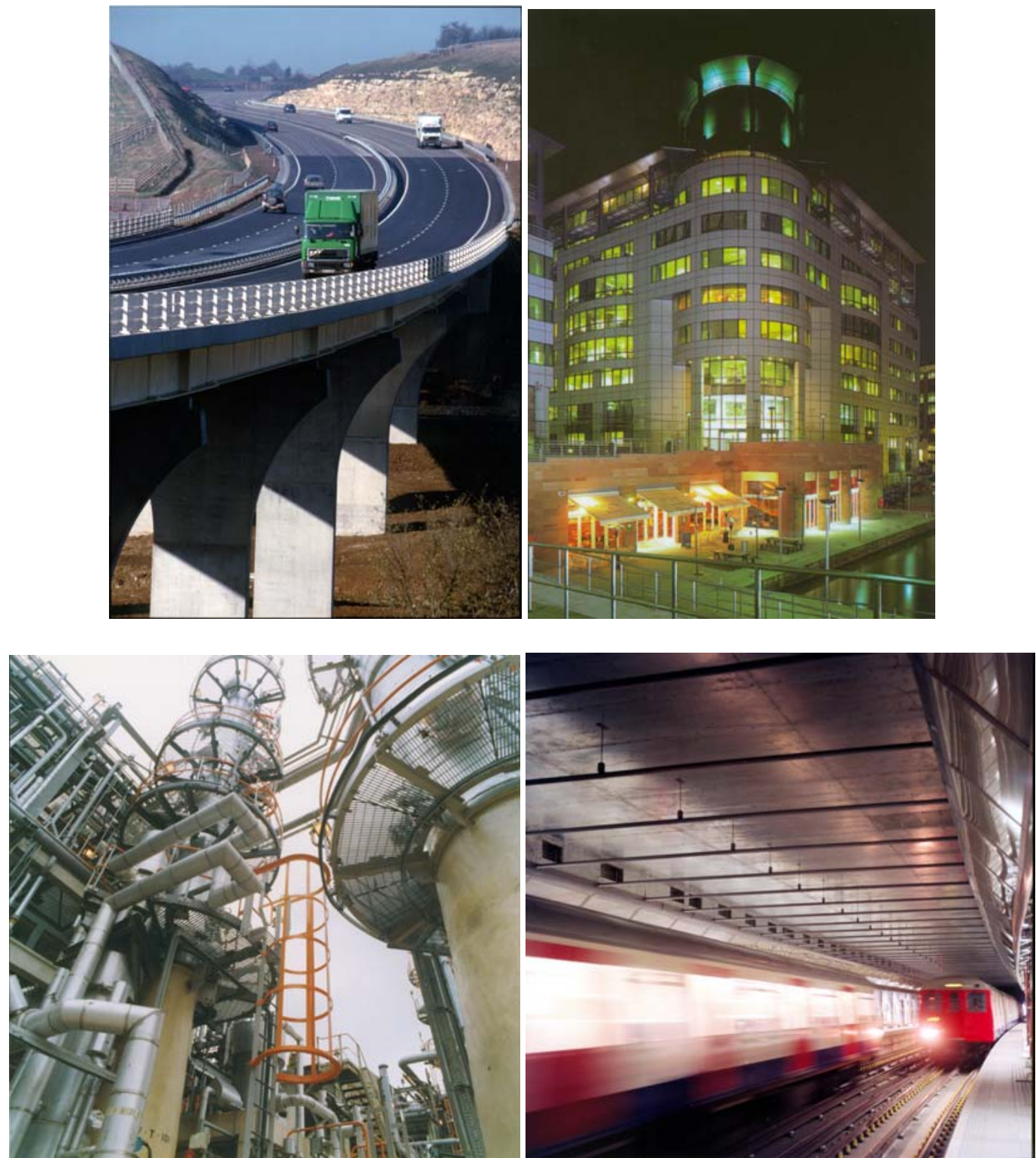

Figure 4 Different types of project: unique products but repeatable processes 

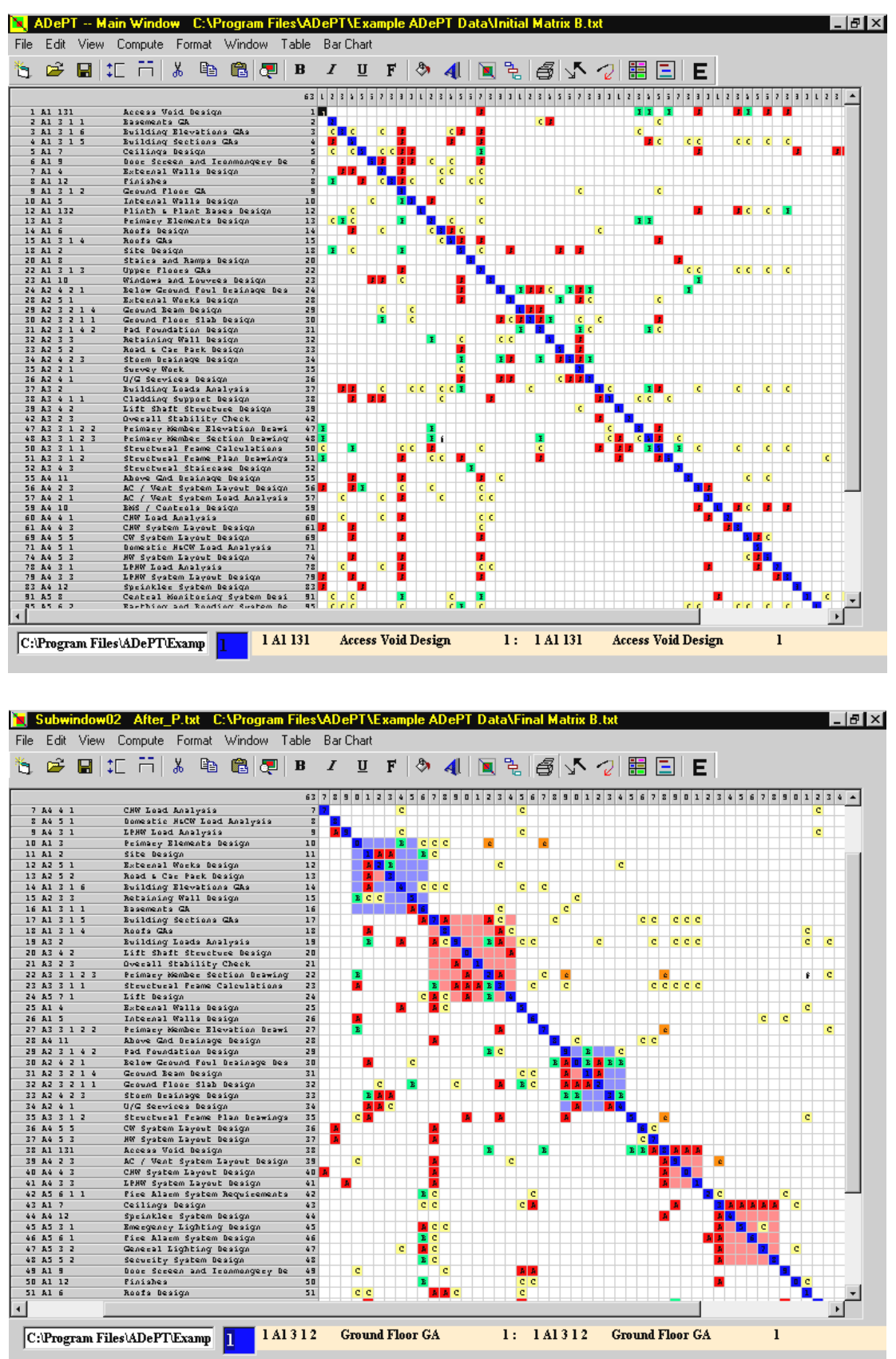

Figure 5 A simple example of Dependency Structure Matrix analysis 


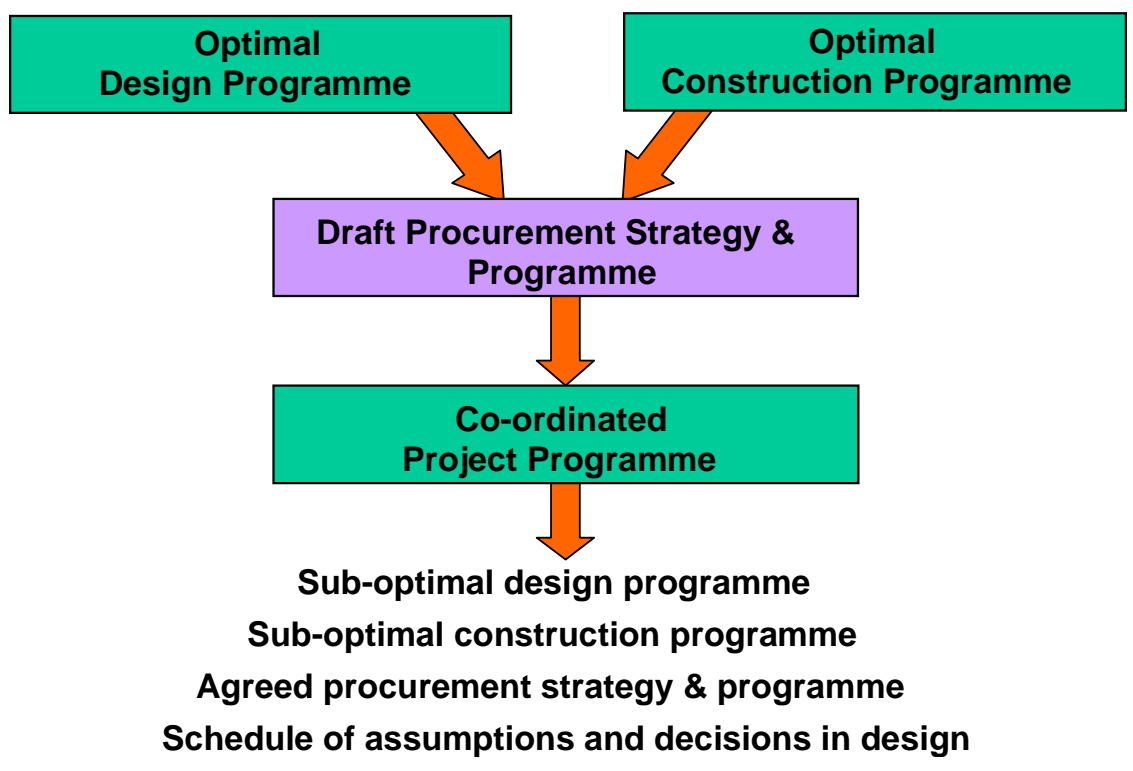

Figure 6 A schematic of the integration of design and construction processes

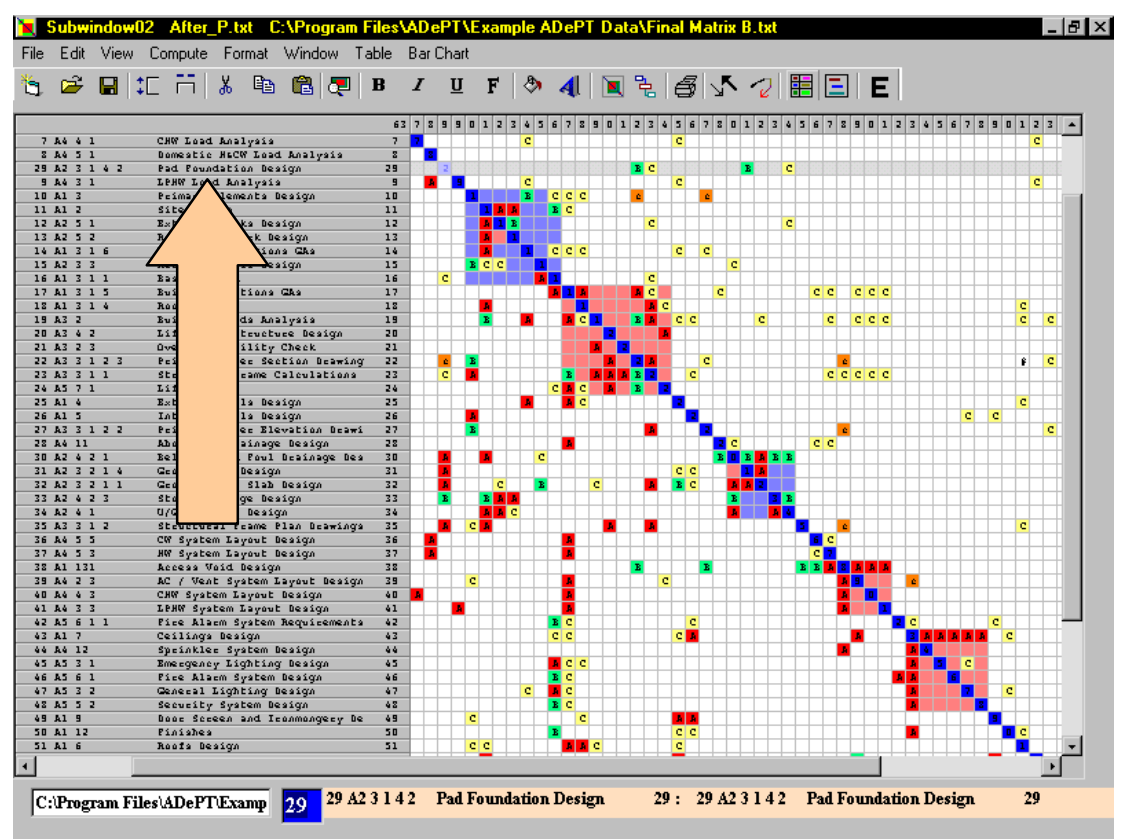

Figure 7 A matrix with constraint analysed 